\title{
Burnout and Empathic Tendency Levels in Emergency Nurses
}

\author{
Tuğba Çınarlı', Zeliha Koç², Latif Duran ${ }^{3}$ \\ 'Department of Emergency Medicine Nursing, Ondokuz Mayıs University Health Science Institute, Samsun, Turkey \\ 2Department of Nursing, Ondokuz Mayıs University Health Science Faculty, Samsun, Turkey \\ ${ }^{3}$ Department of Emergency Medicine, Ondokuz Mayıs University School of Medicine, Samsun, Turkey
}

\begin{abstract}
Aim: It is important to determine the factors affecting burnout and empathic tendency levels among emergency nurses in order to increase satisfaction with healthcare service in patients and their relatives and to increase the quality of healthcare services. The purpose of the present study was to determine the factors that affect burnout and empathic tendency levels among emergency nurses.

Material and Methods: This was a descriptive and cross-sectional study. Data were collected using the Nurse Identification Form, the Maslach Burnout Inventory (MBI), and the Empathic Tendency Scale (ETS).

Results: A total of 129 emergency nurses participated in the study. Among the nurses, $22.5 \%$ were males. The mean MBI score of nurses who partially willingly chose the profession, did not like their job, and had poor or very poor quality of work life was found to be higher. The mean ETS score of nurses who willingly or partially willingly chose the profession and who liked their job was higher.
\end{abstract}

Conclusion: Because empathic skills and tendency can be improved with education, the empathic tendency skills of nurses should be improved through continuous education programs.

Keywords: Emergency nursing, empathic tendency, maslach burnout inventory, self-awareness

\section{Introduction}

In the healthcare system, burnout is a frequent problem in professions, particularly in nursing, where services are directly provided to individuals. Burnout has a personal nature, but it can lead to the loss of professional productivity, challenges in under taking professional responsibilities, and loss of institutional efficiency (1-4). Maslach defined burnout "as a syndrome seen in individuals who are exposed to intense emotional demands due to their occupation and are asked to work face-to-face with other individuals, which is caused by fatigue, long-term exhaustion, hopelessness, and desperate feelings being reflected out with negative behaviors shown toward occupation, life, and other people" (5).

Emergency services in Turkey have very stressful and exhausting environments because simultaneous care is provided to patients with various health problems and critical decisions need to be made in a short time (2). Compared with other clinics of hospitals, emer- gency services are very crowded places where unplanned visits need to be made and various duties ranging from non-emergency procedures to resuscitation are performed (6). Additional factors such as the excessive number of patients, limited number of nurses, long working hours, shift work, provision of care for patients in need of extensive and immediate care, emotional stress linked to working conditions, insufficient wages, lack of appreciation by executives, and lack of support from colleagues may lead to exhaustion in emergency healthcare professionals, particularly in nurses (7-10).Accordingly, previous studies have reported that emergency nurses are more likely to experience burnout due to emotional exhaustion, depersonalization, and job-related stress because they face more challenging and life-threatening situations than nurses working in other services $(1,9,11,12)$.

Work-related burnout may negatively affect nurses' understanding of and communication with patients and relatives, which in turn may result in not being fully able to meet patients' needs. Ultimately,

\section{Correspondence to: Tuğba Çınarlı e-mail: tugba.cinarli@omu.edu.tr}

\section{Received: 29.07.2016 Accepted: 30.11.2016}


this may result in reduced empathic tendencies in nurses. Empathic tendency, which makes up the emotional dimension of empathy, is defined as the ability to understand the emotional problems of individuals and the desire to help individuals who have such problems $(13,14)$. Empathic tendency is one of the professional qualities nurses need to possess; however, the level of burnout can negatively affect the use of this quality. In this regard, it is very important to determine the factors affecting the burnout and empathic tendency levels of emergency nurses in order to increase satisfaction with healthcare service in patients and their relatives and to increase the quality of healthcare services.

\section{Material and Methods}

\section{Study design}

This descriptive and cross-sectional study aimed to determine the factors that affect the burnout and empathic tendency levels of emergency nurses. The study was conducted between May 1 and May 28, 2016. The sample was obtained from a group of 136 nurses who were working at the emergency services of 5 public hospitals and a university hospital. A total of 129 nurses who volunteered to participate in the study and who worked at an emergency service during the past 6 months were recruited. Nurses who were on leave or excused on the day the questionnaires were administered, who did not agree to participate in the study, and who did not complete the questionnaires were excluded from the study $(n=7)$. The response rate in the present study was $94.9 \%$.

The research questions of the present study, which recruited emergency nurses, were as follows: (1) What are the sociodemographic and professional characteristics of emergency nurses? (2) What is the level of burnout and empathic tendency in emergency nurses? (3) Do the sociodemographic and professional characteristics of emergency nurses affect their levels of burnout and empathic tendency? (4) Is there an association between burnout and empathic tendency in emergency nurses?

Data were collected using the Nurse Identification Form, the Maslach Burnout Inventory (MBI), and the Empathic Tendency Scale (ETS). The Nurse Identification Form consists of 33 questions on sociodemographic and occupational characteristics. MBI was developed by Maslach and Jackson in order to determine the "Emotional Exhaustion,"'Depersonalization," and "Personal Accomplishment" levels of individuals with regard to their occupation (5). Ergin conducted the Turkish validity and reliability study of MBI in Turkish nurses (15). MBI contains 22 items and 3 sub-dimensions titled Emotional Exhaustion, Depersonalization, and Personal Accomplishment. Responses for each item are rated as " $0=$ Never," " $1=$ Very rarely," " $2=$ Sometimes," "3=Often," and "4=Always." Total scores can range between 0 and 88 . Higher scores indicate higher levels of burnout.

Empathic Tendency Scale is a Likert-type scale developed by Dökmen (16) in order to measure the empathic tendencies of individuals. ETS consists of 20 items scored by the respondents on the basis of the level of agreement on a scale ranging from 1 to 5 . In reverse scored items, a score of 1 corresponds to the statement "I completely agree" and a score of 5 corresponds to "I completely disagree". Higher scores indicate higher empathic tendency levels.

In a pilot study, the survey form was tested on 5 nurses. Data obtained from the pilot study were not included in the actual study. The participants were informed about the study, and written informed consent was obtained before data collection. It was explained that participation in the study was voluntary, that personal information such as one's name should not be written on the questionnaires, and that findings of the study will only be used for research purposes. It took approximately 10-12 minutes to complete the survey form. Permission to conduct the study was obtained from the Ethics Committee of the Ondokuz Mayis University (04.14.2016, Decision No: B.30.2.ODM.020.08/234-299). Additional permissions were also taken from hospital executives and the university hospital management. In the present study, the Cronbach alpha coefficients of MBI and ETS were found to be 0.76 and 0.59 , respectively.

\section{Statistical analysis}

Data were analyzed using the Statistical Package of Social Sciences version 21 (IBM SPSS Statistics; Armonk, NY, USA) software. Normality was examined using the Shapiro-Wilk method. The Mann-Whitney $U$ and Kruskal-Wallis tests were conducted to analyze non-normally distributed data, whereas the independent samples t-test and 1-way analysis of variance (ANOVA) were used to analyze normally distributed data. Reliability of the scales was measured with Cronbach alpha analysis. The associations between scale scores were examined using Spearman's correlation coefficient. Results were presented as frequencies, percentages, means, standard deviations, and medians (minimum-maximum). The level of statistical significance was accepted as $p<0.05$.

\section{Results}

A total of 129 emergency nurses participated in the present study. It was found that $77.5 \%$ of the participants were females, $22.5 \%$ were males, $62.8 \%$ were married, $38 \%$ had associate degrees, $31 \%$ had Bachelor's degrees, $77.5 \%$ were on the permanent staff, 92.2\% were service nurses, $80.6 \%$ worked continuous shifts, $42.6 \%$ were partially satisfied with working in the emergency service, and 39.5\% defined their job satisfaction level as average (Table 1).

The mean MBI score was 44, and the mean Emotional Exhaustion, Depersonalization and Personal Accomplishment sub-dimension scores of $\mathrm{MBI}$ were 19,6 , and 19 , respectively (Table 2). It was determined that the mean $\mathrm{MBI}$ scores showed significant differences according to willingly choosing the profession $(p<0.001$, $\left.\chi^{2}=16.056\right)$, liking the job $\left(\mathrm{p}<0.001, \chi^{2}=21.811\right)$, and quality of work life $\left(p<0,001, \chi^{2}=18,744\right)$, while the mean MBI scores did not show significant differences according to age $\left(p=0.264, \chi^{2}=3.977\right)$, marital status $(p=0.411, U=1775.5)$, gender $(p=0.901, U=1430)$, education level $\left(p=0.964, \chi^{2}=0.276\right)$, employment status $(p=0.191, U=1218.5)$, assignment in the emergency service $(p=0.937, U=586)$, work schedule $(p=0.620, U=1217)$, and employee satisfaction in the emergency service $\left(p=0.181, \chi^{2}=3.422\right)$. In light of these findings, it can be said that the mean $\mathrm{MBI}$ scores of nurses who partially willingly chose the profession, were dissatisfied with their job, and had poor or very poor quality of work life were higher (Table 3).

The mean ETS score was determined as $73.96 \pm 9.80$ (Table 2). It was found that the mean ETS score showed significant differences according to willingly choosing the profession $\left(p=0.981, \chi^{2}=0.0038\right)$ and liking the job $\left(p=0.046, \chi^{2}=6.177\right)$, while the mean ETS score did not show significant differences according to age $(p=0.865$, $\left.\chi^{2}=0.650\right)$, marital status $(p=0.536, U=1817)$, gender $(p=0.101$, $\mathrm{U}=1160)$, education level $\left(\mathrm{p}=0.964, \chi^{2}=0.276\right)$, employment status $(p=0.285, t=1.070)$, assignment in the emergency service $(p=0.729$, 
Table 1. Distribution of sociodemographic and professional characteristics of nurses

\begin{tabular}{|c|c|c|c|}
\hline Characteristics & & $\mathbf{n}$ & $\%$ \\
\hline \multirow{4}{*}{$\begin{array}{l}\text { Age groups } \\
(30.47 \pm 7.62)\end{array}$} & $18-24$ years & 40 & 31.0 \\
\hline & 25-31 years & 26 & 20.2 \\
\hline & $32-38$ years & 43 & 33.3 \\
\hline & $39-46$ years & 20 & 15.5 \\
\hline \multirow[t]{2}{*}{ Gender } & Female & 100 & 77.5 \\
\hline & Male & 29 & 22.5 \\
\hline \multirow[t]{2}{*}{ Marital status } & Married & 81 & 62.8 \\
\hline & Single & 48 & 37.2 \\
\hline \multirow[t]{4}{*}{ Education level } & Vocational high school & 33 & 25.6 \\
\hline & Associate degree & 49 & 38.0 \\
\hline & Undergraduate & 40 & 31.0 \\
\hline & Bachelor's degree & 7 & 5.4 \\
\hline \multirow[t]{2}{*}{ Employment status } & On permanent staff & 100 & 77.5 \\
\hline & Contracted & 29 & 22.5 \\
\hline \multirow{2}{*}{$\begin{array}{l}\text { Assignment in emergency } \\
\text { service }\end{array}$} & Service nurse & 119 & 92.2 \\
\hline & Service chief nurse & 10 & 7.8 \\
\hline \multirow[t]{2}{*}{ Work schedule } & Day work & 25 & 19.4 \\
\hline & Night shift & 104 & 80.6 \\
\hline \multirow[t]{3}{*}{ Employee satisfaction } & Satisfied & 53 & 41.1 \\
\hline & Not satisfied & 21 & 16.3 \\
\hline & Partially satisfied & 55 & 42.6 \\
\hline \multirow[t]{5}{*}{ Job satisfaction } & Very good & 7 & 5.4 \\
\hline & Good & 33 & 25.6 \\
\hline & Moderate & 51 & 39.5 \\
\hline & Poor & 16 & 12.4 \\
\hline & Very poor & 22 & 17.1 \\
\hline
\end{tabular}

Table 2. Means and standard deviations of MBI and ETS scores

\begin{tabular}{|l|c|}
\hline & AM \pm SD \\
\hline Emphatic Tendency Scale & $73.96 \pm 9.80$ \\
\hline Maslach Burnout Inventory & $44(23-84)$ \\
\hline Maslach Burnout Inventory Sub-dimensions & \\
\hline Emotional Exhaustion & $19(9-26)$ \\
\hline Depersonalization & $6(0-19)$ \\
\hline Personal Accomplishment & $19(6-26)$ \\
\hline A.M: arithmetic mean; SD: standard deviation & \\
\hline
\end{tabular}

$t=-0.348)$, work schedule $(p=0.857, t=0.180)$, employee satisfaction in the emergency service $(p=0.05, F=3.158)$, and quality of work life $\left(p=0.463, \chi^{2}=2.569\right)$. In light of these findings, the mean ETS score was determined to be higher in nurses who willingly or partially willingly chose the profession and who liked their job (Table 3).

\section{Discussion}

Emergency services are very hectic, intense, and stressful working environments where lives are saved and patients in need of immediate assistance are assessed and provided with appropriate care. Therefore, healthcare personnel working at emergency services are more likely to develop burnout (9).

In the present study, the mean MBI score was 44 and the mean Emotional Exhaustion, Depersonalization, and Personal Accomplishment sub-dimension scores of MBI were 19,6 , and 19 , respectively. In other studies examining the burnout levels of nurses and related factors, it was reported that nurses scored between $7.21 \pm 6.74$ and $33.67 \pm 10.82$ on the Emotional Exhaustion sub-dimension, $2.81 \pm 3.35$ and13.67 \pm 7.26 on the Depersonalization sub-dimension, and $11.6 \pm 4.7$ and $36.80 \pm 7.91$ on the Personal Accomplishment sub-dimension $(4,9,17-24)$. Previous studies have provided inconsistent results regarding the MBI total and sub-dimension scores among nurses. This inconsistency may be explained by the differences in the sociodemographic and occupational characteristics of nurse samples, including age, gender, marital status, working conditions, work load, working hours, work schedule, and professional experience.

In the present study, it was determined that the mean MBI scores were significantly higher in nurses who partially willingly chose the profession, disliked their job, and had very poor or poor quality of work life. Previous studies have supported our findings and reported that age $(18,23)$, gender $(23)$, education level $(18,23)$, marital status $(18,23)$, work schedule $(18,23)$, and duties (23) do not affect burnout levels of nurses. On the other hand, other studies with contradicting results have indicated that age, gender, marital status, education level, income, family structure, childbearing status, employment duration, satisfaction with wages, shift work, daily and monthly working hours, overtime work, and workplace relationships are associated with the Emotional Exhaustion and Depersonalization sub-dimensions of MBI $(2-4,9,17-26)$.

Factors that affect burnout levels in nurses may vary according to methodology. Nevertheless, a number of studies have demonstrated that voluntary occupational choices, satisfaction with professional life, education level, and income affect burnout levels $(17,19,24)$. In addition, it has been reported that women suffer more from emotional exhaustion than men; that personal perceptions, emotional exhaustion, and depersonalization levels of nurses who work shifts are generally higher; and that depersonalization reduces with increased employment duration (22). In the same study, it was found that gender is not associated with burnout in nurses, while other studies $(22,24)$ indicated that gender is an important variable affecting MBI scores. This inconsistency in the literature can be explained by the fact that there is a high number of female nurses who constitute the majority of study samples and that there is only a small number of male emergency nurses. Furthermore, the choice of occupation seems to be an important factor that can negatively affect burnout levels among nurses as well as one's personal and work life. An individual who willingly practices his/her profession would have higher levels of job satisfaction and perceived success, which in turn reduce burnout levels.

In the present study, it was determined that age and professional experience did not affect burnout levels. However, in a previous study, it was found that the burnout level reduces with increased age and professional experience and that younger and less experienced 
Table 3. Comparison of MBI and ETS scores according to sociodemographic and professional characteristics

\begin{tabular}{|c|c|c|c|c|c|}
\hline & & \multicolumn{2}{|c|}{ Empathic Tendency Scale } & \multicolumn{2}{|c|}{ Maslach Burnout Inventory } \\
\hline & & $\begin{array}{c}\text { Med (Min-Max) } \\
\text { AM } \pm \text { SD }\end{array}$ & $\begin{array}{c}\text { p Value } \\
\text { Test Value }\end{array}$ & Med (Min-Max) & $\begin{array}{l}\text { p Value } \\
\text { Test Value }\end{array}$ \\
\hline \multirow[t]{4}{*}{ Age } & 18-24 years & $73.5(53-100)$ & \multirow{4}{*}{$\begin{array}{c}p=0.865 \\
\chi 2=0.650\end{array}$} & $43.5(28-63)$ & \multirow{4}{*}{$\begin{array}{l}\chi^{2}=3.977 \\
p=0.264\end{array}$} \\
\hline & 25-31 years & $73(56-88)$ & & $47.5(23-84)$ & \\
\hline & $32-38$ years & $74(53-98)$ & & $45(30-62)$ & \\
\hline & $39-46$ years & $76.5(56-100)$ & & $42.5(27-50)$ & \\
\hline \multirow[t]{2}{*}{ Marital status } & Married & $74(53-100)$ & \multirow{2}{*}{$\begin{array}{l}\mathrm{p}=0.536 \\
\mathrm{U}=1817\end{array}$} & $45(27-84)$ & \multirow{2}{*}{$\begin{array}{l}U=1775.5 \\
p=0.411\end{array}$} \\
\hline & Single & $73.5(54-100)$ & & $44(23-63)$ & \\
\hline \multirow[t]{2}{*}{ Gender } & Female & $74(53-100)$ & \multirow{2}{*}{$\begin{array}{l}p=0.101 \\
U=1160\end{array}$} & $44(23-84)$ & \multirow{2}{*}{$\begin{array}{l}U=1430 \\
p=0.901\end{array}$} \\
\hline & Male & $72(56-85)$ & & $44(27-55)$ & \\
\hline \multirow[t]{4}{*}{ Education level } & Medicine career college & $74(54-100)$ & \multirow{4}{*}{$\begin{array}{c}p=0.964 \\
\chi 2=0.276\end{array}$} & $41(23-58)$ & \multirow{4}{*}{$\begin{array}{c}\chi^{2}=0.276 \\
p=0.964\end{array}$} \\
\hline & Associate degree & $74(53-93)$ & & $44(28-63)$ & \\
\hline & Undergraduate & $73.5(53-100)$ & & $46(30-84)$ & \\
\hline & Bachelor's degree & $70(56-84)$ & & $49(38-58)$ & \\
\hline \multirow[t]{2}{*}{ Employment status } & Staffed & $74.46 \pm 10.07$ & \multirow{2}{*}{$\begin{array}{l}p=0.285 \\
t=1.070\end{array}$} & $44.5(27-84)$ & \multirow{2}{*}{$\begin{array}{l}U=1218.5 \\
p=0.191\end{array}$} \\
\hline & Contracted & $72.24 \pm 8.76$ & & $44(23-63)$ & \\
\hline \multirow{2}{*}{$\begin{array}{l}\text { Assignment in } \\
\text { emergency service }\end{array}$} & Service nurse & $73.87 \pm 9.96$ & \multirow{2}{*}{$\begin{array}{l}p=0.729 \\
t=-0.348\end{array}$} & $44(23-84)$ & \multirow{2}{*}{$\begin{array}{c}U=586 \\
p=0.937\end{array}$} \\
\hline & Service chief nurse & $75.00 \pm 8.00$ & & $44(36-53)$ & \\
\hline \multirow[t]{2}{*}{ Work schedule } & Day work & $74.28 \pm 9.11$ & \multirow{2}{*}{$\begin{array}{l}p=0.857 \\
t=0.180\end{array}$} & $44(28-53)$ & \multirow{2}{*}{$\begin{array}{l}U=1217 \\
p=0.620\end{array}$} \\
\hline & Night shift & $73.88 \pm 10.00$ & & $44(23-84)$ & \\
\hline \multirow{3}{*}{ Employee satisfaction } & Satisfied & $75.43 \pm 10.87$ & \multirow{3}{*}{$\begin{array}{c}p=0.05 \\
F=3.158\end{array}$} & $43(23-63)$ & \multirow{3}{*}{$\begin{array}{c}\chi 2=3,422 \\
p=0.181\end{array}$} \\
\hline & Not satisfied & $73.43 \pm 10.75$ & & $44(28-84)$ & \\
\hline & Partially satisfied & $72.75 \pm 8.22$ & & $46(30-59) \mathrm{B}$ & \\
\hline \multirow{3}{*}{$\begin{array}{l}\text { Willingness in choice } \\
\text { of profession }\end{array}$} & Willingly & $74(53-100)$ & \multirow{3}{*}{$\begin{aligned} p & =0.981 \\
\chi 2 & =0.0038\end{aligned}$} & $43(23-62) A$ & \multirow{3}{*}{$\begin{array}{c}\chi 2=16.056 \\
p<0.001\end{array}$} \\
\hline & Partially willingly & $74(53-100)$ & & 47 (30-59)B & \\
\hline & Unwillingly & $72.5(56-98)$ & & $47.5(34-84) A B$ & \\
\hline \multirow[t]{3}{*}{ Status of liking the Job } & Likes & $74.50(53-100)$ & & $42(23-66) A$ & \\
\hline & Dislikes & $69(56-88)$ & $p=0.046$ & $48(38-63) B$ & $\chi 2=21.811$ \\
\hline & Indecisive & $74(53-100)$ & & $46(27-84) A B$ & $p<0.001$ \\
\hline Quality of worklife & Very good & $73.5(53-79)$ & & $42(25-55) A B$ & \\
\hline & Good & $75(53-79)$ & $p=0.463$ & $43(23-63) A$ & $\chi 2=18.744$ \\
\hline & Poor & $72(54-100)$ & $\chi 2=2.569$ & $47(30-84) B$ & $\mathrm{p}<0.001$ \\
\hline & Very poor & $73(53-93)$ & & $49(40-59) B$ & \\
\hline
\end{tabular}

nurses have higher burnout levels (27). Other relevant studies have reported that the problem solving skills of nurses improve with age and increased experience (3) and that nurses who do not find their job to be suitable for them and who are dissatisfied with their work life have higher burnout levels (17).

In the present study, the mean ETS score was found to be 73.96 \pm 9.80 . In a study by Özcan (28), which investigated factors related to the empathic tendency and skills of nurses, the mean ETS score was reported to be $65.95 \pm 10.66$. In another study conducted for determining the association between empathy and job satisfaction in nurses working at a university hospital, the mean ETS score was found to be101.33 \pm 14.07 (10). In a study by Köksal and Üstün (20), which examined the relationship between empathic tendency and burnout in nurses, the mean ETS score was reported to be $69.95 \pm 7.89$.In conclusion, mean ETS scores vary across studies. This variation may be linked to numerous sociodemographic and profes- 
sional characteristics of nurse samples, such as age, gender, marital status, work load, working hours, work schedule, insufficient nursing staff, personal features, and education level.

It was determined that willingly choosing the nursing profession and liking the profession affected ETS scores and that nurses who willingly or partially willingly chose the profession and those who liked their job had higher ETS scores. On the other hand, it was demonstrated that ETS scores did not show significant differences according to age, marital status, gender, education level, employment status, assignment to the emergency service, type of employment, satisfaction with working at the emergency service, quality of work life, and job satisfaction.

Previous studies that support our findings have shown that age, marital status, gender, education level, employment status, employment duration, and satisfaction with the working environment do not affect ETS scores in nurses $(10,28,29)$. However, other studies have indicated that gender, education level, work unit, assignment, and weekly working hours affect nurses' communication and empathic skills $(29,30)$. It has also been reported that the ETS scores are higher among nurses who are married and have children, who are health high school graduates, and who have a working duration of 10 years and more at the current unit $(10,28)$. Lastly they drew attention to the plausibility that high empathic tendencies can lead to burnout, even though no relation was found in between the two in this research (31). Finally, the present study showed that there was no association between empathic tendency and gender. This finding can be explained by the fact that male nurses adopt an empathic approach toward their patients, similar to female nurses.

\section{Study limitations}

In the present study, data were collected using self-report burnout and empathic tendency questionnaires. Empathic tendency and burnout levels of nurses were not evaluated through observations and repeated measures, which is an important limitation of the present study. Thus, it is recommended that future studies should employ qualitative research methods as well as quantitative methods such as carrying out focus groups with nurses.

\section{Conclusion}

In the present study, it was determined that nurses who partially willingly chose the profession, disliked their jobs, and had poor or very poor quality of work life had higher burnout levels, while nurses who willingly or partially willingly chose the profession and who liked their jobs had higher empathic tendency levels. It is recommended that personal and work-related factors, which affect empathic tendency and burnout in nurses, should be addressed and that the effects of working conditions on nurses should be periodically evaluated by executives. In addition, patient loads should be reduced and working conditions as well as the physical working environment should be improved. Finally, it is of crucial importance to include the topic of empathic tendency in nursing education and in graduate continuous education programs.

Ethics Committee Approval: Ethics committee approval was received for this study from the ethics committee of Ondokuz Mayıs University School of Medicine (04.14.2016, Decision No: B.30.2.ODM.020.08/234-299).
Informed Consent: Written informed consent was obtained from patients who participated in this study.

Peer-review: Externally peer-reviewed.

Conflict of Interest: No conflict of interest was declared by the authors.

Financial Disclosure: The authors declared that this study has received no financial support.

\section{References}

1. Barutcu E, Serinkan C. Burnout syndrome as one of the most important issues of today and a research in Denizli. Ege Academic Journal of Perspectives 2008; 8: 541-61.

2. Kavlu I, PInar R. Effects of job satisfaction burnout on quality of life in nurses who work in emergency services. Turkish Clinics' J Med Sci 2009; 29: 1543-55.

3. Kaya N, Kaya H, Ayık SE, Uygur E. Burnout of nurses who work in a government hospital. International Journal of Human Sciences 2010; 7: 401-19.

4. Öztürk S, Özgen R, Şişman H, Baysal D, Sarıakçalı N, Aslaner E, et al. Burnout of Nurses Working in a University Hospital and the Effect of Social Support. Çukurova Medical Journal 2014; 39: 752-64.

5. Maslach C, Jackson SE. The measurement of experienced burnout. J Organiz Behav. 1981; 2: 99-113. [CrossRef]

6. Kallberg AS. Patient safety in the emergency department - errors, interruptions and staff experience (dissertation). Stockholm, Sweden: Karolinska Institute 2015.

7. Croke EM. Nurses, negligence, and malpractice. Am J Nurs 2003; 103: 5463. [CrossRef]

8. Günüşen NP, Üstün B. Burnout in the nurses and doctors working in secondary healthcare services in Turkey: A literature review. Dokuz Eylül Üniversitesi Hemşirelik Yüksek Okulu Elektronik Dergisi 2010; 3: 40-51.

9. Kebapçı A, Akyolcu N. The Effects of the work environment on nurse burnout in emergency department. Turk J Emerg Med 2011; 11: 59-67. [CrossRef]

10. Özdemir S, Tözün M, Ünsal A, Danacı B, Sözmen MK. Levels of empathy and its relation with job satisfaction among nurses in an university hospital. Smyrna Medical Journal 2015: 30-8.

11. Potter $C$. To what extent do nurses and physicians working within the emergency department experience burnout: a review of literature. Australas Emerg Nurs J 2006; 9: 57-64. [CrossRef]

12. Derin N, Demirel ET. Burnout syndrome the effects of organizational commitment on review of nurses who work in Malatya center. Süleyman Demirel University The Journal of Faculty of Economics and Administrative Sciences 2012; 17: 509-30.

13. Öz F. Relation between empathic tendencies, empathic skills and academic successes of final year nursing students. Cumhuriyet University Journal of School of Nursing 1998; 2: 53-8.

14. Dökmen Ü. Communiation Conflicts and Empathy. Istanbul. 2003.

15. Ergin C. Adaptation of burnout and Maslach Burnout Inventory to doctors and nurses. VII National Congress of Psychology Scientific Studies, Ankara 1993: 143-54.

16. Dökmen Ü. Measurement of Empathy based on a new model and based on psychodrama. Ankara University Journal of Health Sciences 1988; 21: 155-90.

17. Taycan O, Kutlu L, Çimen S, Aydı N. Relationship between depression and burnout levels of nurses working in an university hospital with socio-demographic properties. Anatolian Psychiatry Journal 2006; 7: 100-8.

18. Metin Ö, Özer FG. Determination of the level of nursing burnout. Atatürk University Journal of School of Nursing 2007; 10: 58-66.

19. Şahin D, Turan FN, Alparslan N, Şahin I, Faikoğlu R, Görgülü A. Burnout levels of health staff working in a state hospital. Arch Neuropsychiatry 2008; 45: 116-21. 
20. Köksal H, Üstün B. Determination of the Relationship between Empathic Tendency and Burnout Levels of Nurses (dissertation). İzmir: Dokuz Eylül Univ. 2009.

21. Malak B, Üstün B. The relation between nurses' sociotropy-autonomy personality features and their burnout levels. Hacettepe University Faculty of Health Sciences Nursing Journal 2011; 1-16.

22. Kulakçı H, Ayyıldız T, Veren F, Kalıncı N, Topan A. Evaluation of the mobbing and burnout levels and affecting factors of midwives and nurses working in Zonguldak Public Hospitals. J Edu Res Nurs 2015; 2: 133-41. [CrossRef]

23. Akyüz $i$. Investigation of level of nurses' burnout and depression in terms of working conditions and demographic characteristics. Iş̧letme ve Iktisat Çalışmaları Dergisi 2015; 3: 21-34.

24. Bağcl Z. Study of some demographic properties influencing the burnout levels of nurses in public hospitals by CHAID analysis. Journal of Faculty of Economics and Administrative Sciences 2015; 5: 479-94.

25. Mollaoğlu M, Fertelli TK, Tuncay FÖ. Examination of burnout and autonomy levels in nurses. Community and Physician 2005; 20: 259-66.
26. Okray Z, Abatay GB. The comparison of job burn-out and job satisfaction among nurses of primary health care and inpatient treatment institutions. Turkish International Journal of Special Education and Guidance \& Counseling 2015; 4: 49-56.

27. Brewer EW, Shapard L. Employee burnout: A metaanalysis of the relationship between age or years of experience. Human Resource Development Review 2004; 3: 102-23. [CrossRef]

28. Özcan H. Empathic tendencies and skills of nurses: Sample from Gümüşhane. Gümüşhane University Journal of Health Sciences 2012; 1:60-8.

29. Coşkun F, Durna Z. Evaluation of Empathic Skill Levels of Nurses Working in Internal Medicine and Surgery Services (dissertation). İstanbul: İstanbul Univ. 2011.

30. Şahin ZA, Özdemir FK. Determination of communication and empathy skill levels of nurses. G.O.P. Taksim E.R.H (Education and Research Hospital). JAREN 2015; 1: 1-7.

31. Özçınar M. Burnout Syndrome in Physician Assistants. T.C. (Republic of Turkey), Ministry of Health (dissertation). İstanbul:T.C. Sağlık Bakanlığı. 2005. 